\title{
AOR
}

Selected Papers of \#AoIR2020:

The 22nd Annual Conference of the

Association of Internet Researchers

Virtual Event / 13-16 Oct 2021

\section{NOT YOUR ROBIN HOOD: GAMESTOP AND PLATFORM ECONOMICS AT PLAY}

Mel Stanfill

University of Central Florida

Anastasia Salter

University of Central Florida

\section{Introduction}

In January 2021, a stock market anomaly gained widespread attention: GameStop and AMC, stocks with no discernable reason for an increase in value (particularly given movie theatre closures across the nation), rose abruptly in price. This was soon understood as resulting from manipulation by members of the $r /$ WallStreetBets subreddit. The manipulation was frequently described as "unprecedented" even though it was, as one journalist notes, all-too-familiar: "Why is market manipulation and activist investment acceptable when a billionaire does it but not when an anarchic group of quarantined day traders does? Why is it OK to bet on a company's failure? Pull at these threads long enough, and you might unravel the ideological underpinnings of the financial industry" (Silverman 2021). This underlying tension was only heighted as double standards proliferated: in the face of rising prices on stocks that were heavily shorted, platforms popular with day traders restricted sale on all of the Redditors' targets. We argue that this incident is the inevitable result of treating platforms (and economics) through the lens of gaming and trolling; we examine the role of content moderation practices, coordinated inauthentic action, and toxic technocultures that were formerly confined to popular culture but now spiral outward.

\section{Robinhood Unmasked: Background}

The trading platform most strongly associated with the Reddit incident is, ironically, named Robinhood. Robinhood was already under scrutiny for "gamification" before the GameStop events because it both "turned investing into an online social activity" and made it "too easy, and too fun, to wager money on stocks and more complicated investments" (Massa and Robinson 2020). While such apps are often framed as equalizing the playing field-Robinhood's slogan is "Let the people trade"-they maintain everyday people as second-class participants in the stock market. Robinhood 
users quickly ran up against these limits as the platform "restricted transactions for certain securities to position closing only" along with other apps in its category, ceasing trading of all stocks targeted by the movement mid-surge on January $28^{\text {th }}$, which they blamed on "recent volatility" ("Keeping Customers Informed Through Market Volatility" 2021). At the time of Robinhood's bans, reportedly $56 \%$ of its users owned GameStop stock (Pearson 2021). Backlash against this decision played out across platforms, which we contend is best understood as part of longstanding issues around moderation and trolling.

\section{Closing the Gates: Content Moderation}

The wild rise in prices provoked correspondingly increased attention to content moderation on the platforms the traders used. Most obviously, Robinhood itself restricted their participation. However, the subreddit the traders had used to organize also changed its settings to private temporarily, with one of several explanations provided saying, "We are experiencing technical difficulties based on unprecedented scale as a result of the newfound interest in WSB. We are unable to ensure Reddit's content policy and the WSB rules are enforceable without a technology platform that can support automation of this enforcement" (Peters 2021b). Most notably, the corresponding Discord server was banned "for continuing to allow hateful and discriminatory content after repeated warnings....we did not ban this server due to financial fraud related to GameStop or other stocks" (Peters 2021a). The content moderation situation shows two things: first, the recurring internet company claim that moderation is impossible remains a reflection of their priorities, not their capabilities; and second, while much of the celebratory focus on WSB was about its challenge to capital, that did not automatically make them progressive heroes, as we'll discuss below.

\section{Revolt in the Reviews: Coordinated Action}

In addition to social media outcry, thwarted traders immediately turned to the app store, where Robinhood was targeted by a review bombing campaign. Through collective action, they lowered the app to one star on Google Play reviews. Reviewers were not dissuaded by Google's attempts to mitigate the damage by removing nearly 100,000 reviews (Gartenberg 2021).

This strategy is familiar: review bombing is a practice in which anti-fans (Gray 2003) of a particular media product coordinate to post negative reviews of the product and drive its rating down. Review bombing's appeal as a weapon relies on broader trends in internet culture, such as the replacement of expertise by a flattened field of opinion, the offloading of formerly professional labor onto user-generated content, and the decline of trust in the system that these shifts produce. These changes let malicious actors deliberately manipulate the trust that the voice of "the crowd" or "everyday people" is supposed to provide, using tactics common to a variety of other harmful uses of the internet and with shared reactionary politics. 


\section{Anticapitalist Heroes? The Enemy of My Enemy}

The popular response to the $r /$ WallStreetBets saga was frequently celebratory, seeing their actions as a challenge to capitalism-as opposed to spectacular participation in it. This was questionable on its face because, while at least one hedge fund nearly went bankrupt-needing a bailout from another hedge fund-GameStop executives made billions from their own stock holdings as a result of the price surge.

However, opposition to Wall Street was taken by many to be evidence of progressive politics. Casting Redditors as leftist heroes required ignoring that the platform is known for a toxic technoculture (Massanari 2017). In particular, through longstanding tropes associating Jewish people with capital, anti-capitalism slid easily into anti-Semitism. As one reporter noted, "Fascists on Telegram and in 4chan are elated, gamifying the stock market as a kind of 'GamerGate2,' in which they perceive themselves as fighting an anti-Semitic financial war" (Ross 2021).

\section{Conclusion}

Ultimately, many of the patterns of the Reddit stock incident locate it in a long history of coordinated internet action steeped in toxic technocultures. However, the expansion of these practices into taking direct action on economic systems worth billions of dollars is new and calls for rigorous attention.

\section{References}

Gartenberg, Chaim. 2021. "Robinhood Plummets Back down to a One-Star Rating on Google Play." The Verge. February 1, 2021.

https://www.theverge.com/2021/2/1/22261178/robinhood-google-play-store-apprating-one-star-reviews-stocks-gamestop-reddit.

Gray, Jonathan. 2003. "New Audiences, New Textualities." International Journal of Cultural Studies 6 (1): 64-81. https://doi.org/10.1177/1367877903006001004.

"Keeping Customers Informed Through Market Volatility." 2021. Robinhood.Com. January 28, 2021. https://blog.robinhood.com/news/2021/1/28/keepingcustomers-informed-through-market-volatility.

Massa, Annie, and Edward Robinson. 2020. "Robinhood's Role in the 'Gamification' of Investing." Bloomberg.Com, December 19, 2020.

https://www.bloomberg.com/news/articles/2020-12-19/robinhood-s-role-in-thegamification-of-investing-quicktake.

Massanari, Adrienne. 2017. "\#Gamergate and The Fappening: How Reddit's Algorithm, Governance, and Culture Support Toxic Technocultures." New Media \& Society 19 (3): 329-46. https://doi.org/10.1177/1461444815608807.

Pearson, Jordan. 2021. "Robinhood Stops Users From Trading GameStop Stocks, Other Reddit YOLO Picks." Vice. January 28, 2021. 
https://www.vice.com/en/article/m7ak7y/robinhood-stops-users-from-tradinggamestop-stocks-other-reddit-yolo-picks.

Peters, Jay. 2021a. "Discord Bans the r/WallStreetBets Server, but New Ones Have Sprung to Life." The Verge. January 27, 2021. https://www.theverge.com/2021/1/27/22253251/discord-bans-the-rwallstreetbets-server.

_ 2021b. "R/WallStreetBets Went Private — and Now It's Back with a Message." The Verge. January 27, 2021. https://www.theverge.com/2021/1/27/22253339/reddit-wallstreetbets-subredditprivate-gamestop.

Ross, Alexander Reid. 2021. "Fascists on Telegram and in 4chan Are Elated, Gamifying the Stock Market as a Kind of 'GamerGate2,' in Which They Perceive Themselves as Fighting an Anti-Semitic Financial War. I Won't Post the Slurs, but They See Capitalism as a Jewish Conspiracy and Go from There. Https://T.Co/FZcmtnwhJp." Tweet. @areidross (blog). January 27, 2021. https://twitter.com/areidross/status/1354491483219324928.

Silverman, Jacob. 2021. "The GameStop Saga Shows How Casino Capitalism Is Eating the World." The New Republic, January 27, 2021. https://newrepublic.com/article/161082/gamestop-saga-shows-casino-capitalismeating-world. 